\title{
OTIMIZAÇÃO NA PRODUÇÃo DE CELULASES DE Bacillus sp. POR CULTIVO EM FASE SUBMERSA A PARTIR DO RESÍDUO PÓ DE TABACO
}

\author{
SCHERER, R. L. 1; SCHUCH, E. M. K. 2; ROTH, J. C. G. ${ }^{\text {; } ~ H O E L T Z, ~ M . ~ 4 ; ~ B E N I T E Z, ~ L . ~ B . ~}{ }^{4}$
}

PALAVRAS-CHAVE: Resíduo. Bacillus sp. Pó de Tabaco. Planejamento estatístico.

\begin{abstract}
RESUMO
A destinação dos resíduos produzidos pelas agroindústrias para a produção de biocompostos tem sido uma alternativa ambiental adequada, além de permitir a agregação de valor a esses materiais. Neste estudo foram avaliados os melhores fatores abióticos para condução de um cultivo submerso utilizando-se uma bactéria do gênero Bacillus sp., isolada do resíduo pó de tabaco, através do planejamento experimental de Composto Central (CC) e da análise de superfície de resposta para a produção de celulases totais (FPase). 0 design de CC avaliou 3 fatores, e 5 pontos centrais, e a atividade enzimática determinada como resposta (UI $\left.\mathrm{mL}^{-1}\right)$. $0 \mathrm{pH}$, temperatura e a agitação foram mantidas fixas, e os fatores, concentração do resíduo ( $\mathrm{g} \mathrm{L}^{-1}$ ); quantidade de inóculo bacteriano (\%); e concentração de Tween 80 (\%), avaliados em 5 diferentes níveis. A matriz de planejamento e a avaliação das respostas foram obtidas através do software Statistica 8, e as respostas submetidas a ANOVA (95\%). A avaliação das superfícies de respostas demonstrou que a melhor condição experimental para a condução do processo fermentativo seria obtida quando a concentração de surfactante Tween 80 (\%) fosse mantida em $4 \%$, inóculo bacteriano em $12 \%$ e concentração de substrato em $15 \%$. 0 resíduo pó de tabaco se mostrou adequado como substrato para o processo fermentativo e devido a sua grande disponibilidade regional, pode ser utilizado como indutor da produção de celulases, permitindo sua valorização e minimização dos impactos negativos ao meio ambiente, resultantes da falta de gerenciamento adequado.
\end{abstract}

\section{SUBMERGED CULTIVATION OF Bacillus Sp. USING TOBACCO WASTE FOR CELLULASE PRODUCTION}

KEYWORDS: Waste. Bacillus sp. Tobacco Powder. Statistical planning.

\begin{abstract}
The destination of residues produced by agroindustries for the production of biocomposites has been an adequate environmental alternative, in addition to allowing added value to these residual materials. In this study, the best abiotic factors for conducting a submerged culture were evaluated using the bacteria of the genus Bacillus sp., Isolated from the tobacco powder residue, through the experimental design of Central Compound (CC) and the analysis of the response surface for the production of total cellulases (FPase). The CC design evaluated 3 factors, and 5 central points, and the enzyme activity determined as a response ( $\left.\mathrm{UI} \mathrm{mL}^{-1}\right)$. The $\mathrm{pH}$, temperature and agitation were kept fixed, and the factors, concentration of the residue ( $\left.\mathrm{g} \mathrm{L}^{-1}\right)$; amount of bacterial inoculum (\%); and Tween 80 concentration (\%), evaluated at 5 different levels. The planning matrix and the evaluation of the responses were obtained using the software Statistica 8, and the responses were submitted to ANOVA (95\%). The evaluation of the response surfaces shows that the best experimental condition for the conduction of the fermentation process would be obtained when the concentration of Tween 80 surfactant (\%) was maintained at $4 \%$, bacterial inoculum at $12 \%$ and substrate concentration at $15 \%$. Tobacco powder residue proved to be an adequate substrate for the fermentation process and due to its great regional availability, it can be used as an
\end{abstract}

${ }^{1}$ Acadêmica do Curso de Farmácia da Universidade de Santa Cruz do Sul - UNISC. E-mail: renata96scherer@gmail.com

${ }^{2}$ Acadêmico do Curso de Engenharia Química da Universidade de Santa Cruz do Sul - UNISC. E-mail: elton_schuh1@hotmail.com

3Professora Pesquisadora - Universidade Estadual do Rio Grande do Sul- UERGS. E-mail: joyce_goncalvez@hotmail.com

4Professora Pesquisadora - Programa de Pós-Graduação em Tecnologia Ambiental da Universidade de Santa Cruz do Sul - UNISC. E-mail: michelehoeltz@gmail.com

5Professora Pesquisadora - Programa de Pós-Graduação em Tecnologia Ambiental da Universidade de Santa Cruz do Sul - UNISC. E-mail: lisianne@unisc.br 
inducer of cellulases production, allowing its valorization and minimizing the negative impacts to the environment, resulting from the lack of proper management.

\section{INTRODUÇÃO}

Os processos que geram produtos biotecnológicos têm obtido cada vez mais importância no desenvolvimento da tecnologia ao redor do mundo. A necessidade de evoluir para um novo sistema econômico, baseado na integração de conhecimentos para o uso sustentável dos recursos está cada vez mais em evidência, através da redução da geração de resíduos e da poluição, bem como da diminuição na emissão de gases de efeito estufa (JARAMILLO, 2018).

A geração de resíduos e subprodutos é inerente a qualquer setor produtivo. 0 aumento da conscientização ecológica, iniciado no final do Século XX, deixou claro que o grande desafio da humanidade para as próximas décadas é equilibrar a produção de bens e serviços, crescimento econômico, igualdade social e sustentabilidade ambiental (COSTA et al., 2012).

O Brasil representa o segundo maior mercado produtor de fumo em folha e mantém, há alguns anos, sua posição de maior exportador de fumo no mercado mundial. Apesar das exportações de fumo em folha não representarem uma participação expressiva na balança comercial brasileira, a cultura do fumo apresenta grande relevância na produção agrícola e na renda gerada em determinadas localidades do país, principalmente na região Sul, que responde por mais de $90 \%$ da produção nacional de fumo (VARGAS et al., 2012).

Resíduos da agroindústria de tabaco geram problemas ambientais, principalmente no solo, onde a deposição ocorre sem controle, uma vez que, algumas moléculas e metabólitos presentes no resíduo podem acidificar ou alcalinizar excessivamente o meio, o que poderia inibir o crescimento microbiano ou reduzir a atividade dos microrganismos no solo (LAUSCHNER et al., 2013). Em razão disso, outras alternativas ambientalmente adequadas precisam ser exploradas para viabilizar a gestão adequada desse material residual (LAUSCHNER et al., 2012).

A utilização de resíduo pó de tabaco, como matéria-prima para a produção de enzimas, é viável pelo seu baixo custo econômico, alta disponibilidade e resolução dos problemas relacionados à poluição. A produção de celulases a partir desta matéria-prima tem como principais motivadores a abundância desses materiais, ricos em nutrientes, contribuindo com a sustentabilidade dos sistemas de produção. Além das celulases agirem como degradadores de materiais lignocelulósicos e na detoxificação de resíduos agroindustriais (MACIEL et al., 2014).

Desta forma, este estudo teve por objetivo avaliar os melhores fatores abióticos para a condução de um cultivo submerso utilizando-se uma bactéria do gênero Bacillus sp., isolada do resíduo pó de tabaco, através do planejamento experimental de Composto Central (CC) e da análise de superfície de resposta a produção de celulases totais (FPase) utilizando o próprio resíduo como substrato.

\section{FUNDAMENTAÇÃO TEÓRICA}

A valorização dos resíduos industriais a partir de sua reciclagem, reutilização e bioconversão em biocompostos de maior valor vem sendo amplamente difundida a partir de novas políticas de tratamento e metodologias de aproveitamento. No âmbito das agroindústrias as tecnologias de produção mais limpa podem 
ser inseridas como instrumento estratégico para a fabricação de bioprodutos a partir da otimização e melhoria da eficiência das etapas produtivas, assim como a redução e emprego do resíduo em tecnologias ambientalmente apropriadas (NAYAK; BHUSHAN, 2019).

Os resíduos industriais gerados durante os processos produtivos é a principal preocupação dos órgãos reguladores ambientais e sanitários, causando muitos efeitos ambientais negativos, além de contaminar fontes hídricas e disseminando doenças. Deste modo buscam-se alternativas em busca de um equilíbrio ambiental, ações que não comprometem a qualidade de vida da população e não prejudiquem áreas destes empreendimentos (TOLLER, 2016).

A indústria processadora da folha do tabaco gera um resíduo conhecido como pó de que é normalmente descartado em solos agrícolas como fertilizante. No entanto, não se tem conhecimento dos efeitos desta prática à longo prazo. Por isso a busca por tecnologias de aprimoramento dos processos produtivos que tenham por objetivo reduzir e, ou remediar os resíduos gerados se fazem necessárias, diminuindo por consequência o efeito danoso associado e a qualidade do meio ambiente (LAUSCHNER et al., 2012; BENITEZ et al., 2019).

Os microrganismos necessitam de nutrientes, especialmente carboidratos, para crescerem ou se multiplicarem. Em sua maioria, estas moléculas são polímeros de elevado peso molecular, dificultando o acesso às células microbianas. Deste modo, se faz necessário que o microrganismo libere enzimas para o meio extracelular para que o substrato seja degradado e absorvido (NUNES, 2017).

A celulose, presente em muitos resíduos da agroindústria, é um biopolímero abundante que pode ser hidrolisado pela enzima celulase, produzida por alguns microrganismos. A celulase se apresenta como um complexo multienzimático que consegue romper as ligações glicosídicas da celulose, resultando na liberação de oligossacarídeos, celobiose e glicose. São enzimas amplamente utilizadas em diversos ramos da indústria, porém um obstáculo para sua aplicação industrial é o seu levado custo de produção, por conta disto estudam-se alternativas para sua produção (DELATORRE, 2010).

As enzimas são proteínas que atuam como catalisadoras de reações químicas, sendo essenciais para o sistema metabólico de todos os organismos vivos e possuem um papel fundamental na degradação da matéria orgânica. São bastante ativas e versáteis, não requerem altas temperaturas e valores extremos de pH e executam uma variedade de transformações de modo seletivo e rápido em condições brandas de reação, o que torna altamente desejável o seu uso como catalisadores. Geralmente, os processos industriais que empregam enzimas são relativamente simples, fáceis de controlar, eficientes energeticamente e requerem investimentos de baixo custo (OLIVEIRA et al., 2013).

0 processo de fermentação submersa ou cultivo em fase líquida, consiste na solubilização dos nutrientes para a fermentação em meio líquido. Neste processo, podem ser utilizados diversos resíduos da agroindústria para a produção de enzimas microbianas. A fermentação submersa é uma técnica bastante utilizada para a produção de enzimas devido à facilidade de crescimento dos microrganismos em condições controladas de pH e temperatura, além de facilitar a recuperação das enzimas extracelulares (ORLANDELLI et al., 2012). 
0 processamento da biomassa lignocelulósica proveniente dos resíduos agroindustriais, além de ser uma alternativa ambiental adequada, pode ser economicamente atraente para a criação de bioprodutos de interesse comercial, agregando valor ao resíduo. A utilização de cepas microbianas nativas que apresentem alta atividade de celulases é de grande importância, portanto as propriedades destas biomoléculas devem ser bem estudadas para melhorar a eficiência dos processos (ROTH et al., 2020).

\section{MATERIAIS E MÉTODOS}

A partir do resíduo pó de tabaco, isolou-se uma bactéria do gênero Bacillus sp. Para o preparo do inóculo, o microrganismo foi cultivado em ágar nutriente (AN) (extrato de carne 1,0 g $\mathrm{L}^{-1}$, extrato de levedura 2,0 g $\mathrm{L}^{-1}$, peptona 5,0 $\mathrm{g} \mathrm{L}^{-1}$, cloreto de sódio 5,0 $\mathrm{g} \mathrm{L}^{-1}$, Agar 15,0 $\mathrm{g} \mathrm{L}^{-1}$ ) por 24-48 horas e inoculado em caldo BHI (Brain Heart Infusion) (Infuso cérebro coração 17,5\%, peptona 10\%, dextrose 2\%, cloreto de sódio 5\%, fosfato dissódico 2,5\%) mantido a $35^{\circ} \mathrm{C}$ overnight, sob agitação (160 rpm), com concentração inicial determinada pela densidade óptica (0,9 a 1) a $600 \mathrm{~nm}$. Posteriormente, diferentes volumes de inóculo foram acionados ao caldo de cultivo estéril, preparado previamente com a concentração de substrato (pó de tabaco), concentração de Tween 80, substrato e volume de inóculo conforme matriz de planejamento representada na Tabela $1.0 \mathrm{pH}$ do $\mathrm{meio}$ foi mantido fixo em 5 , a temperatura em $70^{\circ} \mathrm{C}$ e agitação em $180 \mathrm{rpm}$.

Depois de 48 horas, alíquotas do caldo fermentativo foram centrifugadas durante 20 minutos, à temperatura de $4 \mathrm{C}^{\circ}$ e velocidade de agitação de $3500 \mathrm{rpm}$, para coleta do sobrenadante (extrato enzimático) utilizado para a determinação da atividade Fpase ( $\mathrm{Ul} \mathrm{mL}^{-1}$ ). A atividade FPase total foi determinada a partir da metodologia proposta por Miller (1959) e Ghose (1987).

Tabela 1 - Matriz de planejamento do Design de composto central com 3 fatores, e 5 pontos centrais

\begin{tabular}{ccccc}
\hline Ensaio & Inóculo $(\mathbf{m L})$ & Substrato $\left(\mathbf{g ~ L}^{-1}\right)$ & Tween $\left(\mathbf{g ~ L} \mathbf{-}^{-1}\right)$ & $\begin{array}{c}\text { Fpase } \\
\left(\text { Ul } \mathbf{~ m L}^{-1}\right)\end{array}$ \\
\hline 1 & 5,00 & 10,00 & 1,00 & 3,46 \\
2 & 5,00 & 10,00 & 3,50 & 3,29 \\
3 & 5,00 & 30,00 & 1,00 & 2,04 \\
4 & 5,00 & 30,00 & 3,50 & 3,82 \\
5 & 10,00 & 10,00 & 1,00 & 4,34 \\
6 & 10,00 & 10,00 & 3,50 & 2,32 \\
7 & 10,00 & 30,00 & 1,00 & 2,31 \\
8 & 10,00 & 30,00 & 3,67 \\
9 & 3,29 & 20,00 & 2,25 & 4,01 \\
10 & 11,70 & 20,00 & 2,25 & 1,76 \\
11 & 7,50 & 3,18 & 2,25 & 1,76 \\
12 & 7,50 & 36,82 & 2,25 & 2,72 \\
13 & 7,50 & 20,00 & 0,15 & 2,20 \\
14 & 7,50 & 20,00 & 4,35 & 2,20 \\
15 & 7,50 & 20,00 & 2,25 & 2,24 \\
16 & 7,50 & 20,00 & 2,25 & 2,86 \\
17 & 7,50 & 20,00 & 2,25 & 2,86 \\
18 & 7,50 & 20,00 & 2,25 & 2,25 \\
19 & 7,50 & 20,00 & 2,25 & \\
\hline \hline
\end{tabular}


Em tubos de ensaio de $15 \mathrm{~mL}$, foram adicionados $1 \mathrm{~mL}$ de tampão citrato $1 \mathrm{~mol} \mathrm{~L}^{-1}, \mathrm{pH} \mathrm{4,8}$ ao substrato (tiras de papel filtro Whatman $n^{\circ} 1$ ). Posteriormente, $0,5 \mathrm{~mL}$ do extrato enzimático foram adicionados e incubados durante 60 minutos a temperatura de $50{ }^{\circ} \mathrm{C}$. Para inibir a atividade enzimática, foram adicionados $3 \mathrm{~mL}$ de DNS (ácido 3,5-dinitro-salicílico) aos tubos, que foram mantidos em banho-maria de $100^{\circ} \mathrm{C}$, durante 5 minutos. Após esse período, os tubos foram resfriados até temperatura ambiente para que pudessem ser analisados através da leitura da absorbância por espectroscopia UV-Vis a 540 nm (MILLER, 1959).

\section{RESULTADOS E DISCUSSÃO}

Os resultados referentes aos parâmetros avaliados no estudo podem ser observados na Tabela 2. A partir dos coeficientes, constituiu-se a equação de segunda ordem (eq. 1), onde o Y descreve a atividade de FPase em U $\mathrm{mL}^{-1}$, I representa a concentração de inóculo (em \%), R a concentração de resíduo (em \%), e, T a concentração de Tween (em \%).

(1)

$$
\begin{gathered}
Y(\text { FPase })=5 \\
\quad .330126-0.798462 I+0.063232 I^{2}+0.060813 R-0.001643 R^{2}-0.402268 T \\
\left.+0.053149 T^{2}-0.004335+0.026920-0.003530\right)
\end{gathered}
$$

A Tabela 2 demonstra a análise da variância (ANOVA) do modelo quadrático da superfície de resposta para a produção de celulase pelo isolado Bacillus sp, onde o erro associado ao modelo previsto (Teste de ajuste ou Lack of fit) não é significativo ( $p>0.05$ ), demonstrando que o modelo previsto se ajusta bem aos dados obtidos experimentalmente. $0 \mathrm{R}^{2}$ do modelo (equação quadrática), explica cerca de $68 \%$ dos dados obtidos experimentalmente. Uma maneira de verificarmos se o modelo ajustado está adequado, é olharmos o resultado do coeficiente de determinação $\mathrm{R}^{2}$. Este coeficiente mede o quanto a variável resposta é explicada pelo modelo.

Tabela 2 - Análise da variância (ANOVA) do modelo quadrático da superfície de resposta para a produção de

\begin{tabular}{|c|c|c|c|c|c|}
\hline Fator & SS & df & MS & $f$ & $p$ \\
\hline (1)Inóculo(L) & 1.30998 & 1 & 1.309984 & 10.92438 & 0.029788 \\
\hline Inóculo(Q) & 2.13197 & 1 & 2.131974 & 17.77922 & 0.013515 \\
\hline (2)Resíduo(L) & 2.81044 & 1 & 2.810445 & 23.43721 & 0.008393 \\
\hline Resíduo(Q) & 0.36851 & 1 & 0.368509 & 3.07311 & 0.154469 \\
\hline (3)Tween(L) & 0.02158 & 1 & 0.021576 & 0.17993 & 0.693255 \\
\hline Tween(Q) & 0.09410 & 1 & 0.094104 & 0.78476 & 0.425734 \\
\hline $1 \mathrm{~L}$ por $2 \mathrm{~L}$ & 0.09396 & 1 & 0.093961 & 0.78357 & 0.426056 \\
\hline 1L por 3L & 0.05662 & 1 & 0.056616 & 0.47214 & 0.529770 \\
\hline $2 \mathrm{~L}$ por $3 \mathrm{~L}$ & 0.01558 & 1 & 0.015576 & 0.12989 & 0.736767 \\
\hline Teste de ajuste & 2.86125 & 5 & 0.572250 & 4.77217 & 0.077588 \\
\hline Erro puro & 0.47966 & 4 & 0.119914 & & \\
\hline Total SS & 10.51050 & 18 & & & \\
\hline
\end{tabular}
celulase pelo isolado Bacillus sp.

SS: soma dos quadrados; df: graus de liberdade; MS: quadrados médios; f: valor f; p: valor $p$ 
Observa-se, a partir da Tabela 2 que são significativos $(\mathrm{p}<0.05)$ os fatores lineares: \% inóculo e \% resíduo, e o fator quadrático, \% inóculo. A normalidade dos resíduos é uma suposição essencial para que os resultados do ajuste do modelo de regressão linear sejam confiáveis. Podemos verificar essa suposição por meio da análise da normalidade e aleatoriedade dos resíduos, que devem estar aleatoriamente dispersos em torno de zero. Ambas a condições são verificadas, o que é esperado quando o modelo se ajusta aos dados experimentais.

As condições empregadas no processo fermentativo foram otimizadas para a produção de celulases determinada pela atividade da FPase (celulase total). A Figura 1 demonstra os gráficos de superfície de resposta gerados pelo software e que demonstra as interações entre a concentração de Resíduo (\%) e Tween (\%) (A), Inóculo (\%) e Tween (\%) (B) e Resíduo (\%) e Inóculo (\%) (C).

Figura 1: Interações entre a concentração de Resíduo (\%) e Tween (\%) (A), Inóculo (\%) e Tween (\%) (B) e Resíduo (\%) e Inóculo (\%) (C).

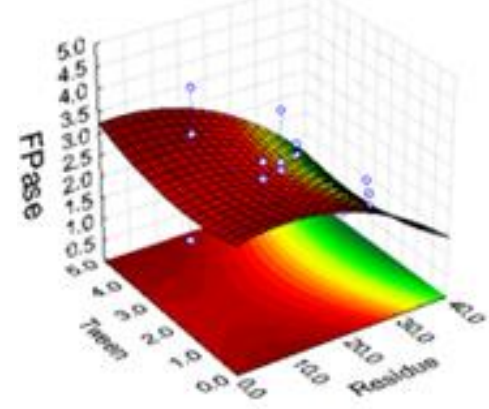

A

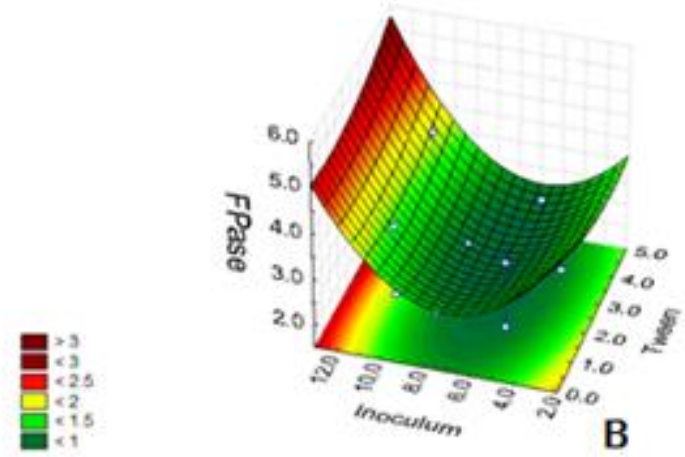

B

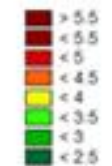

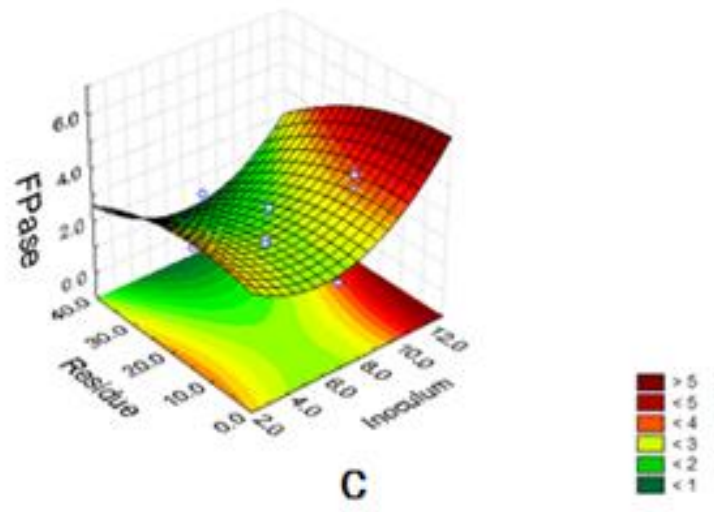

A avaliação das superfícies de respostas (Figura 1) demonstra que a melhor condição experimental para a condução do processo fermentativo é obtida quando a concentração de surfactante Tween 80 (\%) é mantida em $4 \%$, inóculo bacteriano em $12 \%$ e a concentração de substrato em $15 \%$.

Conforme Oliveira et al. (2017) a utilização de reagentes que tendem a estimular a atividade enzimática são de extrema importância, como é o caso do Tween 80 utilizado neste trabalho, que contribuiu na condução do processo fermentativo, promovendo maior adsorção das celulases ao polímero celulósico. Em seu estudo com 
Trichoderma viride, Liu et al. (2006) demonstraram que a adição de surfactantes ao caldo fermentativo, como o Tween 80 , pode estimular a produção de celulases e xilanases.

$0 \mathrm{pH}$ do meio foi mantido fixo em 5 , a temperatura em $70^{\circ} \mathrm{C}$ e agitação em $180 \mathrm{rpm}$, condições que foram definidas devido aos resultados de experimentos prévios empregando o mesmo isolado bacteriano. Segundo o estudo de Irfan et al. (2012) a maioria dos complexos de enzimas celulolíticas, indicam ter maior atividade entre $50^{\circ} \mathrm{C}$ e $60^{\circ} \mathrm{C}$, ou seja, temperaturas elevadas são ideais para a maior atividade enzimática no processo fermentativo. 0 pH ideal está entre 5 a 6,5, pois no decorrer do processo fermentativo o meio sofre alterações de $\mathrm{pH}$, resultante dos nutrientes que podem influenciar para que o meio alcalinize (SIVAKUMAR et al, 2016).

A concentração de substrato que corresponde à melhor condição para o processo fermentativo, neste trabalho, foi de 15\%. Resultados similares conduzidos por Mahato et al. (2020), também demonstram que quando aumentada a concentração de resíduo, neste caso o farelo de trigo, de $1 \%$ para $5 \%$, observou-se um aumento acentuado na produção de enzimas amilases, de 2,25 a 10,51 U L-1.

A pesquisa realizada por Secato et al. (2016) traz a importância de alternativas para substituir os surfactantes sintéticos pela produção de biossurfactantes por Bacillus sp. utilizando um resíduo industrial, rico em glicose, como substrato. 0 mesmo avaliou três diferentes concentrações de inóculo microbiano (5\%, 7,5\% e 10\%). 0s melhores resultados foram obtidos com a máxima concentração de inóculo (10\%), a qual produziu um biossurfactante que foi capaz de reduzir em $36 \%$ a tensão superficial. As demais concentrações apresentaram resultados inferiores, com $14 \%$ de redução quando se utilizou $5 \%$ de inóculo e $20 \%$ de redução com $7,5 \%$ de inóculo.

Em um estudo de otimização das condições de cultivo de Pantoea sp. (ALMEIDA, 2015) para produção de biossurfactantes através de análises estatísticas e avaliação de superfícies de resposta, foram avaliadas três variáveis: gordura vegetal, caldo da casca do abacaxi e milhocina. A condição ótima de produção foi obtida com o meio contendo $2 \%$ de gordura vegetal, $5 \%$ de milhocina e $25 \%$ de resíduo de abacaxi, com redução da tensão superficial em $56,93 \%$.

0 trabalho apresentado por Nagy (2018), avaliou diferentes fontes de carbono e nitrogênio para a produção de biossurfactante de baixo custo a partir de resíduos agroindustriais, utilizando extrato de caju 6,70 g $L^{-1}$, após planejamentos experimentais foi obtido melhor rendimento de tensão superficial de $54,87 \mathrm{mN} / \mathrm{m}$.

Bactérias do gênero Bacillus utilizadas na produção de celulases, são consideradas relativamente seguras para o uso quanto a aspectos ambientais e de saúde, tem efeito potencial para aplicação em processos de cultivo líquido conduzidos em biorreatores, devido a sua elevada taxa de crescimento e menor requerimento de nutrientes adicionados ao meio do cultivo, o que significa o aumento na relação custo-benefício do processo fermentativo.

\section{CONCLUSÃO}

As condições empregadas no processo fermentativo, a partir do planejamento estatístico, foram otimizadas para a produção de celulases por Bacillus sp. A partir de um composto central de 3 fatores, as melhores condições 
foram 4\% de surfactante Tween $80,12 \%$ de inóculo bacteriano e 15\% de resíduo pó de tabaco, a temperatura, $\mathrm{pH}$ e velocidade de agitação fixos em $70^{\circ} \mathrm{C}, \mathrm{pH} 5$ e $180 \mathrm{rpm}$, respectivamente.

Os resultados do planejamento estatístico na otimização são bastante promissores considerando que o pó de tabaco, produzido em grandes quantidades pela indústria do tabaco, ao ser utilizado como indutor da produção de celulases pode aperfeiçoar a eficiência do agronegócio, além de reduzir os impactos negativos ao meio ambiente.

\section{AGRADECIMENTOS}

A UNISC (Universidade de Santa Cruz do Sul) pela oportunidade de realização da bolsa PUIC (Programa UNISC de Iniciação Científica), ao PPGTA (Programa de Pós-Graduação em Tecnologia Ambiental), e ao Centro de Excelência em Produtos e Processos Oleoquímicos e Biotecnológicos que integra o Parque Científico e Tecnológico Regional-Tecno UNISC.

\section{REFERÊNCIAS}

ALMEIDA, F.C.G. Produção de Biossurfactante por Pantoea sp. Utilizando Casca de Abacaxi e Milhocina e Aplicação na Biorremediação. 2015. Tese de Doutorado Faculdade de Engenharia Química, Universidade Estadual de Campinas - UNICAMP, Campinas, SP.

ANOVA - Modelo com Efeitos Fixos, Portal Action, disponível em: http://www.portalaction.com.br/anova/15analise-de-residuos, acessado em 17/03/2020.

BENITEZ, L. B.; ROSA, C. S.; HOELTZ, M.; PFEIFER, A. O.; ROTH, J. C. G. Contribuição para gestão de resíduos na indústria do fumo pela obtenção de celulases a partir do pó de tabaco. Sustentabilidade e responsabilidade social em foco. 1. ed. Belo Horizonte: Poisson, 2019. v. 13. 272p.

COSTA FILHO, D. V.; SILVA, A. J.; SILVA, P. A. P.; SOUSA, F. C. Aproveitamento de Resíduos Agroindustriais na Elaboração de Subprodutos. Revista Brasileira de Tecnologia Agroindustrial. Ponta Grossa - PR. v. 06, n. 01: p. 655-664, 2012.

DELATORRE, A. B. Produção De Celulases Pelo Microrganismo Termofílico Bacillus Sp Smia-2. Universidade Estadual Do Norte Fluminense Darcy Ribeiro. Campos Dos Goytacazes - RJ Fev./ 2010.

IRFAN M, SAFDAR A, SYED Q, NADEEM M. Isolation and screening of cellulolytic bacteria from soil and optimization of cellulase production and activity. Turk J Biochem. 37(3):287-293, 2012.

JARAMILLO, E. H. Bioeconomía: el futuro sostenible. Revista de la Academia Colombiana de Ciencias Exactas, Físicas y Naturales. Bogotá, vol.42, n 164, pág. 188-201, 2018.

LAUSCHNER, M. H.; TEDESCO, M. J.; GIANELLO, C.; BORTOLON, L.; KRAY, C. H.; BARBOSA, D. B. P.; ANDREAZZA R.; Utilização de resíduos de agroindústria fumageira como corretivo de acidez em diferentes solos. Pesq.Agrop. Gaúcha, Porto Alegre, v.18, n.1, p.75-80, 2012.

LAUSCHNER, M. H.; TEDESCO, M. J.; BISSANI, C. A.; BORTOLON, L.; BARBOSA, D. B. P; ANDREAZZA, R.; Decomposição de resíduos de agroindústria fumageira no solo. Ciência e Natura, vol. 35, n. 2, 2013, pp. 1-8 Universidade Federal de Santa Maria, Brasil.

LIU, J. et al. Effect of biosurfactant on cellulase and xylanase production by Trichoderma viride in solid substrate fermentation. Processos Bioquímicos , 41, n. 11, p. 2347-2351, 2006.

MACIEL, T.C. et al. Estudo da influência do pH e da temperatura na produção de celulases por Mucor Circinelloides. XX Congresso Brasileiro de Engenharia Química (COBEQ). Out.,2014. 
MAHATO, R. K.; FATEMA, I. T. RAJAGOPALAN, G. Thermostable, Solvent, Surfactant, Reducing Agent and Chelator Resistant $\alpha$-Amylase from Bacillus Strain IBT108: A Suitable Candidate Enables One-Step Fermentation of Waste Potato for High Butanol and Hydrogen Production. Waste Biomass Valorization, https://doi.org/10.1007/s12649-020-01017-1, 2020.

NAGY, G.M. Produção de Biossurfactantes de Baixo Custo a partir de Resíduos Agroindutriais. 2018. Tese de Mestrado Universidade Federal de Uberlândia - UFU, Uberlândia, MG.

NAYAK, A.; BHUSHAN, B. An overview of the recent trends on the waste valorization techniques for food wastes. Journal of Environmental Management, 233, p. 352-370, 2019

NUNES, K. B. Caracterização bioquímica de bactérias psicrotróficas e produção de enzimas termorresistentes em leite cru. Universidade federal de alagoas centro de ciências agrárias programa de pós-graduação em zootecnia. Rio Largo - Alagoas - Brasil. Out/2017.

OLIVEIRA, A. et al. Utilização de resíduos da agroindústria para a produção de enzimas lipolíticas por fermentação submersa. Revista Brasileira de Produtos Agroindustriais, Campina Grande, v.15, n.1, p.19-26, 2013.

OLIVEIRA, C.T.;RIEGER, T.J.; DAROIT, D. Catalytic properties and thermal stability of a crude protease from the keratinolytic Bacillus sp. CL33A. Biocatalysis and Agricultural Biotechnology, v. 10, p. 270-277, 2017.

ORLANDELLI, R. et al. Enzimas de interesse industrial: produção por fungos e aplicações. SaBios: Rev. Saúde e Biol., v.7, n.3, p.97-109, 2012.

ROTH, J. C. G.; HOELTZ, M.; BENITEZ, L. B.; Current approaches and trends in the production of microbial cellulases using residual lignocellulosic biomass: a bibliometric analysis of the last 10 years. Archives of Microbiology, 2020. https://doi.org/10.1007/s00203-019-01796-9.

SECATO, J.F.F.; COELHO, D.F.; ROSA, N.G.J.; COSTA, L.D.L.; TAMBOURGI, E.B. Biosurfactant production using Bacillus subtilis and industrial waste as substrate. Chemical Engineering Transactions, v.49, p.103-108, 2016.

SIVAKUMAR, N.; ZADJALI, A. A.; BAHRY, S. A.; ELSHAFIE, A.; ELTAYEB, E. A.; Isolation and characterization of cellulolytic Bacillus licheniformis from compost. African Journal of Biotechnology. Vol. 15(43), pp. 2434-2446, 26 October, 2016.

TOLLER, M.; A Transformação de Resíduos Agroindustriais Através de Biodigestores: Uma Gestão SócioAmbiental. Revista Brasileira de Energias Renováveis, v.5, p. 42- 50, Tocantins, 2016.

VARGAS, M. A.; Oliveira, B. F. Estratégias de diversificação em áreas de cultivo de tabaco no Vale do Rio Pardo: uma análise comparativa. Revista de Economia e Sociologia Rural. v.50 no.1 Brasília, 2012. 